\title{
Why We Still Need More Research on the Epidemiology of Huntington's Disease
}

\author{
Jussi O.T. Sipiläa-c Markku Päivärinta ${ }^{d}$ \\ ${ }^{a}$ Department of Neurology, North Karelia Central Hospital, Joensuu, b Division of Clinical Neurosciences, Turku \\ University Hospital, and ' Neurology, University of Turku, Turku, Finland; ${ }^{d}$ Visby Lasarett, Visby, Gotland, Sweden
}

Nearly a quarter of a century ago, the mutation underlying Huntington's disease (HD), a dynamic cytosine-adenine-guanine $(\mathrm{CAG})$ repeat expansion of the Huntingtin (HTT) gene located in chromosome 4, was discovered. We have learned much since then, but more work remains if we are to find a cure for this disease. Perhaps, surprisingly, 144 years after George Huntington gave his speech on chorea, this is also true concerning HD epidemiology.

Like earlier studies, a recent review found HD prevalence to be highest in populations of Caucasian descent at 5.7 per 100,000 [1]. However, a rise has been postulated and both estimates in the traditional prevalence range, but considerably higher figures have also been published recently. In their paper, in this issue of Neuroepidemiol$o g y$, Rawlins et al. [2] review all prevalence studies published to date and provide a meta-analysis confirming a trend of increasing HD prevalence in most populations of Caucasian descent. While their results also confirm that the disease is most prevalent in Caucasian populations, they also point out that more studies of HD epidemiology are needed, not only in South America and Africa but also in Asia and even Central and Eastern Europe.

Increase in population longevity and possibly longer survival of HD patients due to better treatment are easy to agree upon as partial explanations for the rise in prevalence. They are also compatible with the stated finding that there has been no change in HD incidence at least in the UK. Increased awareness complemented by the availability of genetic testing is also compatible with this argument provided that it does not lead to ascertainment of completely new cases that otherwise would not have been diagnosed except to persons at risk being diagnosed earlier and thus live longer with diagnosed HD. Considering that the HTT mutation is not a disease in itself but an autosomal dominantly inherited trait and the subjective element inherent in contemporary diagnostic criteria of manifest $\mathrm{HD}$, this is quite possible.

On the other hand, incidence studies from other Caucasian populations seem to suggest an increasing trend [ 1 , $3]$ and data concerning new mutation rates are incomplete. Furthermore, while we do not know the impact the introduction of genetic testing has had upon case ascertainment and diagnosis, it feels sensible to assume that making a diagnosis in uncertain and improbable cases has become easier and even more common. Many studies have indeed recently noted that a considerable number of new patients have no family history of HD and proportions of late-onset cases (at least 60 years of age at motor onset) have increased (for instance [4-6]). This is also

\section{KARGER}

E-Mail karger@karger.com

www.karger.com/ned
(C) 2016 S. Karger AG, Basel

0251-5350/16/0462-0154\$39.50/0
Jussi O.T. Sipilä, MD

Department of Neurology

North Karelia Central Hospital

Tikkamäentie 16, FI-80210 Turku (Finland)

E-Mail jussi.sipila@utu.fi 
reflected by the relatively high prevalence of HD in older age cohorts $[3,7]$, which in turn indicates that the current population structure of Western societies should be considered when analyzing HD prevalence. A study of possible trends in ages of onset and CAG repeat lengths of newly diagnosed patients would be helpful.

Why would the prevalence be rising only in Caucasian-derived populations? Although the exact molecular mechanisms that lead to instability of the CAG repeat are yet to be elucidated, recent work has shown that CAG expansions of HTT are frequently associated with a certain chromosome 4 haplogroup A and particularly subgroups A1 and A2 [8]. These subgroups are absent from Asian populations with low HD prevalence. In these populations, HD is predominantly associated with haplogroup C, which has a considerably lower expansion risk and possibly even different expansion mechanisms compared to haplogroup A [9]. Furthermore, data from Finland suggest that general population haplogroup distribution differences might explain relatively low $\mathrm{HD}$ prevalences in certain genetic outlier populations of Europe [2]. The existing epidemiological data therefore indicates that haplogroup A variants A1 and A2 need to be investigated to uncover molecular mechanisms that underlie this dynamic repeat expansion and possibly others like it.

Obviously, the high level of heterogeneity shown by the current meta-analysis partly stems from differences in methodology between studies. We should therefore retain a certain level of caution in our interpretation of the results. Nevertheless, Rawlins et al. do show that the prevalence of HD is rising in Caucasian populations, and for most of them, prevalence should currently be considered to be close to or over 10 per 100,000. As the authors state, this should be taken into account when designing healthcare services. What is more, this study also proves that research on both the basic epidemiology of HD in many populations and the molecular mechanisms of repeat expansion dynamics are needed in order to efficiently guide studies aimed at finding a cure for HD.

\section{References}

1 Pringsheim T, Wiltshire K, Day L, Dykeman J, Steeves T, Jette N: The incidence and prevalence of Huntington's disease: a systematic review and meta-analysis. Mov Disord 2012;27: 1083-1091.

2 Rawlins MD, Wexler NS, Wexler AR, Tabrizi SJ, Douglas I, Evans SJW, Smeeth L: The Prevalence of Huntington's Disease. Neuroepidemiology 2016;46:144-153.

3 Sipilä JO, Hietala M, Siitonen A, Päivärinta M, Majamaa K: Epidemiology of Huntington's disease in Finland. Parkinsonism Relat Disord 2015;21:46-49.

4 Almqvist EW, Elterman DS, MacLeod PM, Hayden MR: High incidence rate and absent family histories in one quarter of patients newly diagnosed with Huntington disease in British Columbia. Clin Genet 2001;60:198205.

5 Ramos-Arroyo MA, Moreno S, Valiente A: Incidence and mutation rates of Huntington's disease in Spain: experience of 9 years of direct genetic testing. J Neurol Neurosurg Psychiatry 2005;76:337-342.

6 Koutsis G, Karadima G, Kladi A, Panas M: Late-onset Huntington's disease: diagnostic and prognostic considerations. Parkinsonism Relat Disord 2014;20:726-730.

7 Fisher ER, Hayden MR: Multisource ascertainment of Huntington disease in Canada: prevalence and population at risk. Mov Disord 2014;29:105-114.

8 Warby SC, Montpetit A, Hayden AR, Carroll JB, Butland SL, Visscher H, Collins JA, Semaka A, Hudson TJ, Hayden MR: CAG expansion in the Huntington disease gene is associated with a specific and targetable predisposing haplogroup. Am J Hum Genet 2009;84: 351-366.

9 Warby SC, Visscher H, Collins JA, Doty CN, Carter C, Butland SL, Hayden AR, Kanazawa I, Ross CJ, Hayden MR: HTT haplotypes contribute to differences in Huntington disease prevalence between Europe and East Asia. Eur J Hum Genet 2011;19:561-566. 